\title{
Two year review of maternal mortality at a tertiary care hospital of GMERS, Valsad, Gujarat, India
}

\author{
Darshna M. Patel ${ }^{1}$, Mahesh M. Patel ${ }^{2 *}$, Vandita K. Salat ${ }^{1}$
} ${ }^{1}$ Department of Obstetrics and Gynecology, ${ }^{2}$ Department of Anasthesia, GMERS Medical College, Valsad, Gujarat,
India

Received: 20 March 2018

Accepted: 21 April 2018

*Correspondence:

Dr. Mahesh M. Patel,

E-mail: patelmahesh760@gmail.com

Copyright: (c) the author(s), publisher and licensee Medip Academy. This is an open-access article distributed under the terms of the Creative Commons Attribution Non-Commercial License, which permits unrestricted non-commercial use, distribution, and reproduction in any medium, provided the original work is properly cited.

\section{ABSTRACT}

Background: According to the WHO, 80 of maternal deaths in developing countries are due to direct maternal causes such as haemorrhage, hypertensive disorders and sepsis. These deaths are largely preventable. Maternal mortality ratio (MMR) in India is $167 / 100,000$ live births.

Methods: This retrospective observational study was conducted at GMERS, Valsad. Data regarding maternal deaths from January 2016 to December 2017 were collected and analyzed with respect to epidemiological parameters. The number of live births in the same period was obtained from the labour ward ragister. Maternal mortality rate and Mean maternal mortality ratio for the study period was calculated.

Results: The mean Maternal mortality rate in the study period was $413.3 / 100,000$ births. The maternal mortality ratio (MMR) in India is $167 / 100,000$ live births. More than half of maternal deaths were reported in multiparous patients. More maternal deaths were observed in women from rural areas (67.3\%), unbooked patients (73.3\%) and illiterate women $(65.3 \%)$. Thirty six $(69.3 \%)$ maternal death occurred during postpartum period. Most common delay was first delay $(60.0 \%)$ followed by second delay $(40.0 \%)$. Postpartum haemorrhage $(28.8 \%)$, preeclampsia $(17.3 \%)$, sepsis $(13.46 \%)$ were the major direct causes of maternal deaths. Indirect causes accounted for one third of maternal deaths in our study. Anemia, hepatitis and heart disease were responsible for $13.4 \%, 5.7 \%$, and $1.9 \%$ of maternal deaths, respectively.

Conclusions: Majority of maternal deaths are observed in patients from rural areas, unbooked, and illiterate patients. Hemorrhage, eclampsia and sepsis are leading causes of maternal deaths. Most of these maternal deaths are preventable if patients are given appropriate treatment at periphery and timely referred to higher centers.

Keywords: Anemia, Maternal mortality ratio, Postpartum haemorrhage

\section{INTRODUCTION}

According to the tenth revision of the international classification of diseases (ICD-10) "a maternal death is defined as death of a woman while pregnant or within 42 days of termination of pregnancy, irrespective of the duration and site of pregnancy, from any cause related to or aggravated by pregnancy or its management" (ICD10). ${ }^{1}$ According to the WHO, 80 of maternal deaths in developing countries are due to direct maternal causes such as haemorrhage, hypertensive disorders and sepsis. Remaining 20 of maternal deaths are due to indirect causes such as HIV/AIDS, cardiac diseases, hepatic diseases and anemia account for the. ${ }^{2}$ Almost half a million women die every year from complications during pregnancy and childbirth. About 99 of these women are from developing world with over 90 concentrated in Africa and Asia. According to Sample registration survey, maternal mortality ratio (MMR) in India is 167/100,000 live births. ${ }^{3}$ These deaths are largely 
preventable. Majority of maternal deaths occur between third trimester and the first week after delivery. ${ }^{4}$ The time needed to receive adequate care is the most significant contributor to maternal mortality. According to Thaddeus and Maine, delay can occur at three levels. The first delay is recognizing a problem and deciding to seek care. The second delay is reaching a facility that provides an appropriate level of care. The third delay is receiving adequate and appropriate care. ${ }^{5}$

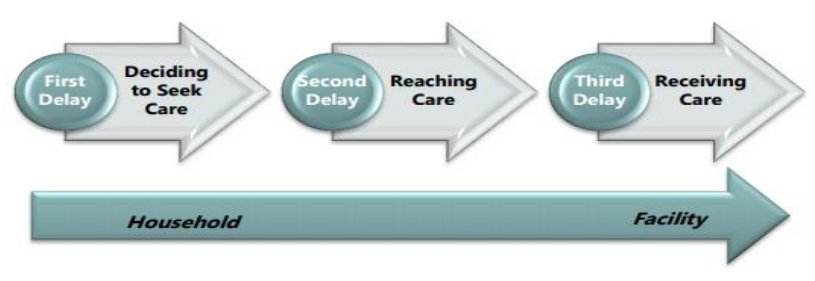

Figure 1: Level of delay (maternal death).

This study was conducted to assess the local causes of maternal mortality in a tertiary medical college hospital situated in semi urban part of Valsad where large numbers of patients are referred from rural parts of south Gujarat.

Aim and objective was to analyse the causes and factors contributing to maternal mortality in referred cases at a tertiary health center.

\section{METHODS}

This retrospective observational study was conducted at GMERS, Valsad which gets a large number of referrals from maternity homes, primary health centers from rural parts of South Gujarat. All women who died due to pregnancy complications during January 2016 to December 2017 were included in the study. Those women died beyond 42 days postpartum were excluded and those who were referred to higher centre and died at that referral centre were also excluded. After obtaining permission from the Medical Superintendent of the hospital, data regarding 52 maternal deaths were collected and analyzed with respect to epidemiological parameters like locality, literacy, gravidity, socio economic status, cause of maternal death. The number of live births in the same period was obtained from the labour ward register. Maternal mortality rate for the study period was calculated by using the formula-

$$
M M R=\frac{\text { Total no of maternal deaths }}{\text { Total no of live births }} \times 100000
$$

Mean maternal mortality ratio for the study period was calculated by calculating the mean of yearly MMR of the entire study period. The data were analysed using Epi info version 7.2 software.

Variables were expressed as frequency and percentage.

\section{RESULTS}

During the study period, there were a total of 12583 live births and 52 maternal deaths. The mean maternal mortality rate was $413.3 / 100000$ live births. The epidemiological characteristics of maternal deaths are given in Table 1.

Table 1: Epidemiological characteristics of maternal deaths $(n=52)$.

\begin{tabular}{|lll|}
\hline Patient characteristics & Number $=52$ & $\%$ \\
\hline Age & & \\
\hline$<20$ & 2 & 3.85 \\
\hline $20-24$ & 27 & 51.92 \\
\hline $25-29$ & 11 & 21.15 \\
\hline $30-34$ & 7 & 13.46 \\
\hline$\geq 35$ & 5 & 9.62 \\
\hline Parity & & \\
\hline Primipara & 21 & 40.38 \\
\hline Multipara & 31 & 59.62 \\
\hline Residence & & 32.69 \\
\hline Urban & 17 & 67.31 \\
\hline Rural & 35 & \\
\hline Antenatal care & & 26.92 \\
\hline Booked & 14 & 73.08 \\
\hline Unbooked & 38 & \\
\hline Education & & 34.62 \\
\hline Literate & 18 & 65.38 \\
\hline Illiterate & 34 & 86.54 \\
\hline Socio economic class & & 11.54 \\
\hline Low & 45 & 1.92 \\
\hline Middle & 6 & \\
\hline High & 1 & \\
\hline & & \\
\hline
\end{tabular}

Mean age of maternal deaths were 26.05 years. Majority of maternal deaths $(38,73.1 \%)$ were reported in the age group of 20 to 29 years. More deaths were reported in multiparous women $(31,59.6 \%)$ as compared to Primiparas $(21,40.4 \%)$.

Table 2: Distribution of maternal deaths according to time, mode of delivery and pregnancy outcome.

\begin{tabular}{|lll|}
\hline \multicolumn{2}{|l|}{ Number } & $\%$ \\
\hline Time of death $(\mathbf{n = 5 2})$ & \multicolumn{2}{l|}{} \\
\hline Antenatal & 13 & 25.00 \\
\hline Intranatal & 3 & 5.77 \\
\hline Postnatal & 36 & 69.23 \\
\hline Route of delivery $(\mathbf{n = 3 9 )}$ & & \\
\hline Vaginal & 29 & 74.36 \\
\hline C-section & 10 & 25.64 \\
\hline Pregnancy outcome & & \\
\hline Live birth & 25 & 64.10 \\
\hline Stillbirth/abortion & 14 & 35.90 \\
\hline
\end{tabular}


Maternal deaths were observed more in women from rural areas $(35,67.3 \%)$ as compared to urban areas $(17$, $32.6 \%)$. Maximum maternal deaths were reported in illiterate women $(34,65.3 \%)$. Seventy three percent of maternal deaths were reported in unbooked patients. Most maternal deaths $(45,86.5 \%)$ were reported in women with low socioeconomic status.

Majority of deaths (36, 69.23\%) occurred during postpartum period followed by antenatal period (13, $25.0 \%)$. Out of 39 birth, 25 (64.10\%) were live birth.

In the study period, $36(69.24 \%)$ of maternal deaths were due to direct causes, while $16(30.76 \%)$ of maternal deaths were due to indirect causes The leading cause of death was uncontrollable postpartum haemorrhage $(15$, $28.8 \%$ ), preeclampsia $(9,17.3 \%)$, anemia $(7,13.46 \%)$, sepsis $(13.46 \%)$ and abruption placenta $(5,9.62 \%)$. Three delays were observed in 40 cases $(76.9 \%)$. Most common delay was delay in recognizing a problem and deciding to seek care $(24,60.0 \%)$ followed by delay in reaching the facility $(16,40.0 \%)$.

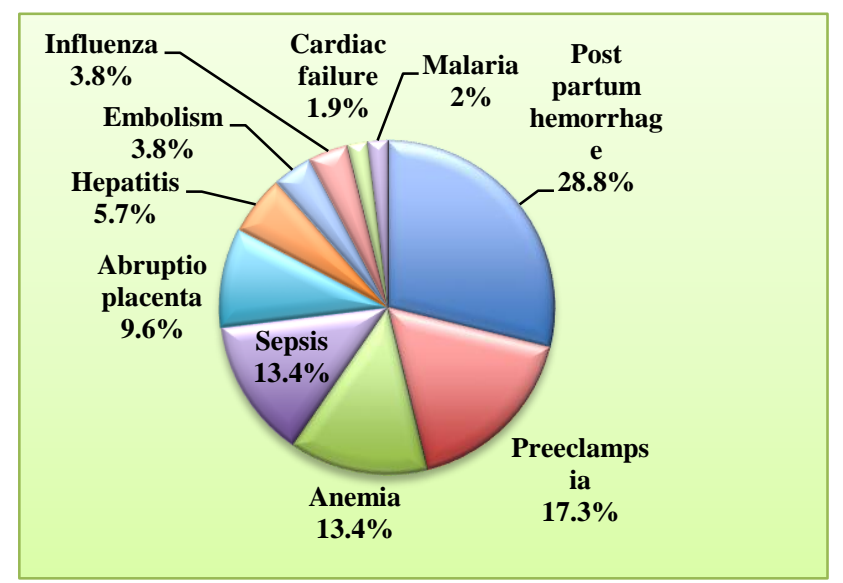

Figure 1: Causes of maternal deaths and its percentages.

\section{DISCUSSION}

Maternal mortality is an indicator of reproductive health of the society. High maternal mortality reflects poor quality of maternal services, late referral and low socioeconomic status of the community. The mean Maternal mortality rate in the study period was 413.3/100000 births. The maternal mortality ratio (MMR) in India is $167 / 100,000$ live births. ${ }^{3}$ Various studies in India in have reported wide variation in MMR (47/100000 to $625 / 100000$ births). ${ }^{6-11}$ Madhu Jain has shown a very high MMR of 2270/100000. ${ }^{7}$

In our study, nearly three fourth of maternal deaths were in the age group of 20 to 29 years. More than half of maternal deaths were reported in multiparous patients. More maternal deaths were observed in women from rural areas $(67.3 \%)$, unbooked patients $(73.3 \%)$, illiterate women $(65.3 \%)$, and women belonging to low socioeconomic status $(86.5 \%)$. Similar findings were reported in studies of Jadhav, Pal and Onakewhor. ${ }^{8-10}$ Thirty six $(69.3 \%)$ maternal death occurred during postpartum period. Prioritization of strategies that focus on professional intrapartum and postpartum care.

In present study, most common delay was first delay $(60.0 \%)$ followed by second delay $(40.0 \%)$. Another study reported first delay was the major contributor $(64.7 \%)$ followed by second delay $(32.0 \%) .{ }^{12}$

In present study, nearly two third of maternal deaths were due to direct causes. Postpartum haemorrhage (28.8\%), preeclampsia $(17.3 \%)$, sepsis $(13.46 \%)$ were the major direct causes of maternal deaths. Our findings were consistent with studies conducted by Jadhav and Shah. ${ }^{8,11}$ Indirect causes accounted for one third of maternal deaths in our study. Anemia, hepatitis and heart disease were responsible for $13.4 \%, 5.7 \%$, and $1.9 \%$ of maternal deaths, respectively. Jain, Jadhav, Pal, and Onakewhor reported similar observation. ${ }^{7-10}$

Most of these maternal deaths can be prevented by ensuring $24 \mathrm{hr}$ availability of basic drugs like tablet misoprostol, injection magnesium sulfate as most maternal deaths are due to post partum hemorrhage and eclampsia. Early detection of high risk pregnancies and referring them to a tertiary center can reduce the complications of high risk pregnancies.

\section{CONCLUSION}

Majority of maternal deaths are observed in patients from rural areas, unbooked, illiterate patients and patients from low socioeconomic status. Hemorrhage, eclampsia and sepsis are leading causes of maternal deaths. Most of these maternal deaths are preventable if patients are given appropriate treatment at periphery and timely referred to higher centers.

\section{Limitation}

We only included patients referred to our hospital, so we can not generalize study finding to general population.

\section{ACKNOWLEDGMENTS}

Authors express sincere gratitude to Dr. Pratixa Chaudhari, Dr. Vandita K Salat, for their valuable suggestions.

\section{Funding: No funding sources \\ Conflict of interest: None declared \\ Ethical approval: The study was approved by the Institutional Ethics Committee}

\section{REFERENCES}

1. World health organization. ICD-10: international statistical classification of diseases and related health problems. Geneva: world health organization; 1992. 
2. Buekens P. Is estimating maternal mortality useful? Bull world health organ. 2001;79(3):179.

3. Special Bulletin on Maternal Mortality in India 2011-13: Sample registration system, Office of Registrar General, India. http://niti.gov.in/content/maternal-mortality-ratiommr-100000-live-births. Accessed 02 January 2018.

4. Ronsmans C, Graham WJ. Maternal mortality: who, when, where, and why. Lancet. 2006;368:1189-200.

5. Thaddeus S, Maine D. too far to walk: maternal mortality in context. Soc Sci Med. 1994;38:1091110

6. Puri A, Yadav I, Jain N. Maternal mortality in an urban Tertiary care hospital of north India. J Obstet Gynaecol India. 2011;61:280-5.

7. Jain M, Maharahaje S. Maternal mortality: A retrospective analysis of ten years in a tertiary hospital. Indian J Prev Soc Med. 2003;34:103-11.

8. Jadhav AJ, Rote PG. Maternal mortality-changing trends. Obstet Gynaecol India. 2007;57:398-400.
9. Pal A, Ray P, Hazra S, Mondal TK. Review of changing trends in maternal mortality in a rural medical college in west Bengal. J Obstet Gynecol India. 2005;55:521-4.

10. Onakewhor JU, Gharoro EP. Changing trends in maternal mortality in a developing country. Niger $\mathbf{J}$ Clin Pract. 2008;11:111-20.

11. Shah RJ, Ali I, Banday A, Fazili A, Khan I. Analysis of maternal mortality in a small teaching hospital attached to tertiary care hospital. Indian $\mathbf{J}$ Community Med. 2008;33:260-2.

12. Iqbal M, Muhammad Z, Akhtar Z, Naz T. The three delays of maternal mortality in a teaching hospital. $\mathbf{J}$ Med Sci. 2017;25(2):231-5.

Cite this article as: Patel DM, Patel MM, Salat VK. Two year review of maternal mortality at a tertiary care hospital of GMERS, Valsad, Gujarat, India. Int J Reprod Contracept Obstet Gynecol 2018;7:2283-6. 